\title{
AT $_{1}$ RECEPTOR BLOCKADE PREVENTS THE INCREASE IN BLOOD PRESSURE AND THE AUGMENTATION OF INTRARENAL ANG II LEVELS IN HYPERTENSIVE Cyp1a1-Ren2 TRANSGENIC RATS FED A HIGH SALT DIET
}

\author{
Dustyn E. Williams, BS, Minolfa C. Prieto, MD, PhD, John J. Mullins, PhD, L. Gabriel Navar, \\ PhD, and Kenneth D. Mitchell, PhD \\ Department of Physiology, Hypertension and Renal Center of Excellence, Tulane University Health \\ Sciences Center, New Orleans, Louisiana; and Center for Cardiovascular Science, University of \\ Edinburgh Medical School, Edinburgh, Scotland
}

\begin{abstract}
Background-The present study was performed to determine the effects of high-salt diet on the magnitude of the increases in systolic blood pressure (SBP) and kidney tissue ANG II levels that occur following induction of ANG II-dependent malignant hypertension in Cyp1a1-Ren2 transgenic rats with inducible expression of the mouse Ren2 renin gene [strain name: TGR (Cyp1a1Ren2)].
\end{abstract}

Methods-Cyp1a1-Ren2 rats ( $\mathrm{n}=6$ ) were fed a normal diet containing $0.3 \%$ indole-3-carbinol (I3C) for 10 days to induce ANG II-dependent malignant hypertension.

Results-Rats induced with I3C exhibited increases in (SBP) and elevations of ANG II levels in kidney cortex and medulla. In a second group of rats $(n=6)$, high salt intake alone did not alter basal SBP; however, subsequent dietary administration of $0.3 \%$ I3C during continued high salt intake elicited a substantially greater increase in SBP than observed in rats fed a normal salt diet. ANG II levels in kidney cortex and medulla of rats induced with $\mathrm{I} 3 \mathrm{C}$ and fed a high salt diet were elevated similarly to those in rats induced with $\mathrm{I} 3 \mathrm{C}$ alone. Chronic administration of the $\mathrm{AT}_{1}$ receptor antagonist, losartan $(100 \mathrm{mg} / \mathrm{L}$ in drinking water, $\mathrm{n}=6)$, markedly attenuated the $\mathrm{I} 3 \mathrm{C}$-induced increase in SBP and prevented the augmentation of ANG II levels in kidney cortex and medulla in rats induced with I3C and maintained on a high salt diet.

Conclusions-Activation of $\mathrm{AT}_{1}$ receptors contributes to the augmented blood pressure and elevated kidney tissue ANG II levels that occur in Cyp1a1-Ren2 transgenic rats with malignant hypertension maintained on a high salt diet.

\section{Keywords}

kidney; renin-angiotensin system; radioimmunoassay; malignant hypertension; sodium-dependent

\section{Introduction}

Transient Induction of ANG II-dependent hypertension has been shown to result in the development of persistent salt-sensitive hypertension in rats. ${ }^{1,2}$ Additionally, it has been demonstrated that long-term infusion of ANG II causes salt-sensitive hypertension in

Address correspondence to: Kenneth D. Mitchell, PhD, FAHA, FASN, Department of Physiology, Tulane University Health Sciences Center, 1430 Tulane Avenue, SL39, New Orleans, LA 70112, Phone: 504-988-2593, Fax: 504-988-2675, kdmitch@tulane.edu. 
experimental animals. ${ }^{3,4}$ The present study was performed to determine if induction of ANG II-dependent malignant hypertension similarly results in the development of salt-sensitive hypertension in Cyp1a1-Ren2 transgenic rats with inducible expression of the mouse Ren2 renin gene [strain name: TGR(Cyp1a1Ren2)]. ${ }^{5}$ This transgenic rat line was created by inserting the mouse Ren 2 renin gene, fused to an $11.5 \mathrm{~kb}$ fragment of the cytochrome P450 1a1 (Cyp1a1) promoter, into the genome of the Fischer 344 rat. ${ }^{5}$ Cyp1a1, which catalyzes the oxidation of a wide range of endogenous lipophilic compounds and xenobiotics ${ }^{6-8}$, is not constitutively expressed, but is highly inducible upon exposure to various aryl hydrocarbons such as indole-3carbinol (I3C).$^{6-12}$ Induction of Cyp1a1 is mediated by the aryl hydrocarbon receptor, which is a basic helix-loop-helix-transcription factor that binds to specific DNA elements in the Cyp1a1 promoter. ${ }^{6,8,13}$ Rats transgenic for the Cyp1a1-Ren2 construct do not constitutively express the Ren 2 renin gene. The Ren 2 gene is expressed primarily in the liver, only upon induction of the Cyp1a1 promoter by aryl hydrocarbons such as I3C. ${ }^{5}$ In this transgenic rat line induction of the Cyp1a1 promoter by dietary administration of $\mathrm{I} 3 \mathrm{C}$ results in a fixed level of expression of the Ren 2 renin gene and in the development of ANG II-dependent hypertension. ${ }^{5,14}$ At a dose of $0.3 \%(\mathrm{wt} / \mathrm{wt}$ ), dietary I3C induces ANG II-dependent malignant hypertension, characterized by rapidly increasing blood pressure, severe renal vasoconstriction and ischemia, pronounced loss of body weight, lethargy, and piloerection. ${ }^{5,14}$ Therefore, this model allows induction of ANG II-dependent malignant hypertension using a benign and naturally occurring dietary supplement without the need for surgical intervention, dietary salt manipulation, or the administration of steroids. 5,14

The mechanisms whereby ANG II-dependent hypertension results in salt-sensitive hypertension remain unclear and an area of intense investigation. It is generally recognized that under normal conditions, increased salt intake inhibits both the circulating and the tissue RAS. In this regard, increasing dietary salt intake to normotensive rats has been shown to reduce both plasma and kidney tissue ANG II levels. ${ }^{15}$ However, evidence is accruing that in several forms of hypertension, high-salt intake results in a paradoxical activation of the RAS. Indeed, the higher systolic blood pressure observed in SHR on a high salt diet is associated with a loss of the usual down-regulatory effect of higher dietary salt intake on the circulating concentration of ANG II and, thus, that the salt-sensitive component of hypertension in SHR is at least in part ANG II-dependent. ${ }^{16}$ Studies in Dahl salt-sensitive rats (DS) have indicated that salt-sensitive hypertension is accompanied by increased activation of the local intrarenal RAS. ${ }^{17}$ In this regard, it has been demonstrated that DS rats fed a high salt diet exhibit an inappropriate augmentation of kidney angiotensinogen and ANG II levels. ${ }^{17}$ In addition, studies have demonstrated that there are paradoxical increases in kidney tissue angiotensinogen mRNA and protein in ANG II-infused rats, and that the urinary excretion of angiotensinogen was significantly increased in ANG II-infused rats, which is associated with an augmentation of intrarenal ANG II levels. ${ }^{18-20}$ Furthermore, renal ANG II concentration was found to be elevated and positively correlated with the blood pressure in the post- ANG II salt-sensitive hypertension model. ${ }^{21,22}$ Similarly, chronic ANG II infusions augment mouse intrarenal ANG II content and increase intrarenal angiotensinogen expression. ${ }^{23}$ Collectively, these data indicate that there is an impaired ability to suppress the activity of the intrarenal RAS in ANG II-dependent hypertensive states and that high salt intake actually causes a paradoxical activation of the RAS. ${ }^{24}$ Such an impaired ability to suppress the activity of the RAS and/or an inappropriately increased activation of the RAS in animals in which circulating ANG II levels are clamped at normal or elevated levels would likely attenuate the vasodilation and natriuresis normally associated with decreasing ANG II levels in response to increasing dietary salt intake. ${ }^{24}$ This would shift the pressure-natriuresis relation to the right and prevent the kidney from excreting a salt load except at elevated arterial blood pressures and, thereby, contribute to salt-sensitivity. ${ }^{24}$ 
Although Cyp1a1-Ren2 transgenic rats develop ANG II-dependent malignant hypertension associated with increased plasma renin activity, and high circulating and intrarenal ANG II levels, the effects of high dietary salt intake on the plasma and intrarenal levels of ANG II in this model remain uncertain. Accordingly, an additional objective was to determine the effects of high salt diet on plasma and kidney tissue ANG II levels in Cyp1a1-Ren2 rats with ANG II-dependent malignant hypertension. In light of the observations that the augmented intrarenal ANG II levels in hypertensive Cyp1a1-Ren2 rats are due in part to $\mathrm{AT}_{1}$ receptor-mediated accumulation of circulating ANG $\mathrm{II}^{14}$, we also determined the effects of $\mathrm{AT}_{1}$ receptor blockade with losartan on the magnitude of the increases in ANG II levels that occur in kidney cortex and medulla following induction of ANG II-dependent malignant hypertension in Cyp1a1Ren2 transgenic rats [TGR(Cyp1a1Ren2)] fed a high salt diet.

\section{Methods}

The experimental procedures in this study conform to the National Institutes of Health Guide for the Care and Use of Laboratory Animals and were approved by the Institutional Animal Care and Use Committee of Tulane University Health Sciences Center. Experiments were performed on adult male transgenic rats [TGR(Cyp1a1Ren2)] with inducible expression of the mouse Ren 2 renin gene..$^{5}$ All transgenic rats used in the present study were bred at Tulane University School of Medicine from stock animals supplied by Harlan UK Limited, Bicester, UK. The experimental animals were divided into five groups. Group 1 (Non-induced; $n=5$ ) Cyp1a1-Ren2 rats were maintained on a normal rat diet (diet TD 99414, Harlan-Teklad, Madison, WI). Group 2 (0.3\% I3C; n=6) Cyp1a1-Ren2 rats were fed a normal diet containing a I3C at a dose of $0.3 \%$ (wt/wt; diet TD 05381, Harlan-Teklad) for 10 days to induce ANG IIdependent malignant hypertension, as described previously. ${ }^{14}$ Group $3(0.3 \% \mathrm{I} 3 \mathrm{C}+\mathrm{Los} ; \mathrm{n}=6)$ rats were fed $0.3 \% \mathrm{I} 3 \mathrm{C}$ and treated chronically with the $\mathrm{AT}_{1}$ receptor blocker losartan (Los; Merck \& Co.) for 10 days. Losartan was added to the drinking water at a concentration of 100 $\mathrm{mg} / \mathrm{L}$. This dose of losartan was used because we observed in pilot experiments it completely prevented the pressor response to intravenous bolus administration of exogenous ANG II, indicating that this dose of losartan elicits substantial blockade of $\mathrm{AT}_{1}$ receptors. Group $4(0.3 \%$ I3C+HS; $n=6)$ rats were fed a high salt diet (8\% NaCl; diet TD92012, Harlan-Teklad)) for 7 days then fed a high salt diet containing 0.3\% I3C (diet TD08046, Harlan-Teklad) for 10 days. Group 5 rats $(0.3 \% \mathrm{I} 3 \mathrm{C}+\mathrm{HS}+\mathrm{Los} ; \mathrm{n}=6)$ were fed a high salt diet $(8 \% \mathrm{NaCl})$ for 7 days, then fed a high salt diet containing $0.3 \% \mathrm{I} 3 \mathrm{C}$ and treated chronically with losartan in their drinking water $(100 \mathrm{mg} / \mathrm{L})$ for 10 days.

Measurement of systolic blood pressure was obtained in conscious rats using tail-cuff plethysmography (IITC Instruments; Woodland Hills, CA). All rats were trained for two weeks prior to the beginning of the experiment in order to habituate them to this procedure. Blood pressures were measured every 1-3 days throughout the duration of the study. Body weight was measured every day throughout the course of the study. At the completion of the experimental protocol, the rats were decapitated between 9.00 AM and noon. The kidneys were excised, drained, weighed, and sectioned sagitally and the cortexes were dissected from the medullas under stereomicroscopy. Kidney cortexes and medullas were then homogenized in chilled methanol in a glass tissue grinder to inactivate ANG II metabolic enzymes and thereby prevent in vitro formation and degradation of angiotensin peptides. The time required to remove, drain, weigh, section and dissect kidney cortexes from medullas did not exceed 120 seconds. ANG II concentrations in kidney tissues were determined by radioimmunoassay as extensively described and validated previously. ${ }^{14,15,25}$ Plasma ANG II was not measured in the present study because we have already demonstrated that chronic administration of an $\mathrm{AT}_{1}$ receptor blocker does not alter PRA or circulating ANG II levels in Cyp1a1-Ren2 rats with malignant hypertension. ${ }^{14}$ This is probably due to the fact that plasma renin and ANG II levels resulting from $\mathrm{I} 3 \mathrm{C}$-mediated induction of hepatic Cyp1a1-Ren2 transgene expression 
are not under the regulation of the juxtaglomerular apparatus mechanisms controlling renin secretion. In essence, plasma renin and ANG II levels in this model are primarily determined by the level of extrarenal expression of the Ren 2 renin gene and are not subject to homeostatic regulation.

Statistical analyses were performed using one-way and two-way ANOVA, one-way repeated measures ANOVA, and two-way repeated measures ANOVA followed by Student-NewmanKeuls test where appropriate. All statistical analyses were performed using SigmaPlot for Windows (version 11, Systat Software Inc., San Jose, CA). Statistical significance was defined as $\mathrm{P}<0.05$. All data are expressed as mean $\pm \mathrm{SE}$.

\section{Results}

The effects of dietary administration of I3C and high salt intake on conscious systolic blood pressure of Cyp1a1-Ren2 transgenic rats are summarized in Fig. 1. Chronic administration of $0.3 \% \mathrm{I} 3 \mathrm{C}$ for 10 days resulted in the development of severe hypertension compared with noninduced controls $(172 \pm 4$ vs. $134 \pm 3 \mathrm{mmHg}, \mathrm{P}<0.001)$. The magnitude of the increase in systolic blood pressure induced by $\mathrm{I} 3 \mathrm{C}$ averaged $46 \pm 7 \mathrm{mmHg}(\mathrm{P}<0.001$; Fig. 1$)$. As shown in Fig. 2, the development of hypertension was associated with a $15 \%$ reduction in body weight (from $365 \pm 5$ to $308 \pm 6 \mathrm{~g}, \mathrm{P}<0.001$ ) and rats induced with $0.3 \% \mathrm{I}$ I C exhibited reduced body weight compared with noninduced rats $(308 \pm 6$ vs. $359 \pm 5 \mathrm{~g}, \mathrm{P}<0.01)$. In addition, the hypertensive rats demonstrated severe lethargy, assumption of a hunched posture, and piloerection, which are manifestations of malignant hypertension in the rat. ${ }^{5,14,26}$ The effects of chronic administration of losartan on blood pressure in rats induced with $0.3 \% \mathrm{I} 3 \mathrm{C}$ are shown in Fig. 1. Chronic administration of losartan $(100 \mathrm{mg} / \mathrm{L}$ in drinking water) did not alter the pattern or magnitude of the increase in systolic blood pressure in rats induced with $0.3 \% \mathrm{I3C}$. The magnitude of the increase in blood pressure in rats induced with $\mathrm{I} 3 \mathrm{C}$ and treated chronically with losartan averaged $44 \pm 8 \mathrm{mmHg}$, a value not different from that in rats induced with I3C alone $(46 \pm 7 \mathrm{mmHg}$ ) (Fig. 1). In contrast, and as shown in Fig. 2, chronic administration of losartan completely abrogated the I3C induced decrease in body weight $(-3 \pm 3$ vs. $-15 \pm 1 \%$, $\mathrm{P}<0.001$ ). Body weight remained unaltered throughout 10 days of $\mathrm{I} 3 \mathrm{C}$ administration and losartan treatment ( $353 \pm 9$ vs. $362 \pm 5 \mathrm{mmHg}, \mathrm{n}=6)$.

The effects of high salt diet on systolic blood pressure are similarly summarized in Fig. 1. High salt intake did not alter basal SBP (127 \pm 4 vs. $128 \pm 4 \mathrm{mmHg})$; however, subsequent dietary administration of $0.3 \%$ I3C during continued high salt intake increased SBP from $128 \pm 4$ to $212 \pm 5 \mathrm{mmHg}(\mathrm{P}<0.001)$ (Fig. 1) and decreased body weight from $309 \pm 22$ to $250 \pm 15 \mathrm{~g}$ $(\mathrm{P}<0.001)$. The increase in SBP induced by I3C in rats maintained on high salt intake was significantly greater than that observed in rats maintained on a normal salt diet $(86 \pm 5$ vs. 46 $\pm 7 \mathrm{mmHg}, \mathrm{P}<0.01$ ) (Fig. 1). The decrease in body weight induced by I3C in rats maintained on a high salt intake was similar to that observed in rats induced with $\mathrm{I} 3 \mathrm{C}$ and maintained on a normal salt diet ( $-18 \pm 2$ vs. $-15 \pm 1 \%$, NS) (Fig. 2). As shown in Fig. 1, chronic administration of the $\mathrm{AT}_{1}$ receptor antagonist, losartan $(100 \mathrm{mg} / \mathrm{L}$ in drinking water, $\mathrm{n}=6)$, markedly attenuated the I3C-induced increase in SBP $(181 \pm 4$ vs. $212 \pm 5 \mathrm{mmHg}, \mathrm{P}<0.01)$ in rats induced with $\mathrm{I} 3 \mathrm{C}$ and maintained on a high salt diet. Similarly, chronic losartan administration prevented the decrease in body weight $(1 \pm 2$ vs. $-18 \pm 2 \%, \mathrm{P}<0.01)$ in rats induced with I3C and fed a high salt diet (Fig. 2).

The effects of high salt and high salt+losartan on ANG II levels in kidney cortex and medulla are summarized in Fig. 3. Cyp1a1-Ren2 rats $(\mathrm{n}=6)$ fed a normal diet containing 0.3\% indole-3carbinol (I3C) for 10 days exhibited elevations of ANG II levels in kidney cortex (215 \pm 29 to $880 \pm 88 \mathrm{fmol} / \mathrm{g}, \mathrm{P}<0.001)$ and medulla $(866 \pm 49$ to $2790 \pm 1038, \mathrm{P}<0.05)$. These findings are consistent with previous observations that Cyp1a1-Ren2 transgenic rats with malignant 
hypertension exhibit augmented total kidney ANG II levels. ${ }^{14}$ As shown in Fig. 3, ANG II levels in kidney cortex and medulla of rats induced with $\mathrm{I} 3 \mathrm{C}$ and fed a high salt diet were elevated similarly to those in rats induced with I3C alone $(1013 \pm 112 \mathrm{vs} .880 \pm 88 \mathrm{fmol} / \mathrm{g}$ and $4043 \pm 1394$ vs. $2790 \pm 1038 \mathrm{fmol} / \mathrm{g}$, respectively). Chronic administration of losartan completely abrogated the I3C induced increases in ANG II levels in kidney cortex and medulla $(300 \pm 20$ vs. $900 \pm 50 \mathrm{fmol} / \mathrm{g}$ and $1500 \pm 100 \mathrm{vs.} 3000 \pm 900 \mathrm{fmol} / \mathrm{g}$, respectively, $\mathrm{P}<0.01$ in both cases) (Fig. 3). Similarly, chronic administration of losartan prevented the augmentation of ANG II levels in kidney cortex $(140 \pm 41 \mathrm{fmol} / \mathrm{g})$ and medulla $(1097 \pm 165 \mathrm{fmol} / \mathrm{g})$ in rats induced with $\mathrm{I} 3 \mathrm{C}$ and maintained on a high salt diet (Fig. 3).

\section{Discussion}

The present study was performed to determine the effects of high-salt diet on the magnitude of the increases in blood pressure and kidney tissue ANG II levels that occur following induction of ANG II-dependent malignant hypertension in Cyp1a1-Ren2 transgenic rats with inducible expression of the mouse Ren 2 renin gene. In the present study, induction of the Ren 2 renin gene by dietary administration of $0.3 \%$ I3C for 10 days resulted in the development of severe hypertension. As described previously ${ }^{14,27}$, the hypertension was associated with a marked decrease in body weight, and the rats exhibited extreme lethargy, assumption of a hunched posture, and piloerection, which are clinical manifestations of malignant hypertension in the rat. ${ }^{5,14,26,27}$ High salt diet alone did not alter basal arterial blood pressure or body weight in non-induced normotensive Cyp1a1-Ren2 transgenic rats. Consistent with our previous findings that total kidney ANG II content is elevated in Cyp1a1-Ren2 rats with malignant hypertension ${ }^{14}$, the $\mathrm{I} 3 \mathrm{C}$-induced increase in blood pressure was associated with increases in the ANG II content in the kidney cortex and medulla. The increase in arterial blood pressure induced by $0.3 \% \mathrm{I} 3 \mathrm{C}$ in rats maintained on a high salt diet was substantially greater than that in rats induced with $\mathrm{I} 3 \mathrm{C}$ and maintained on a normal salt diet. In addition, the increases in renal cortical and medullary ANG II levels in rats maintained on a high salt diet were similar to those in rats induced with $\mathrm{I} 3 \mathrm{C}$ and maintained on a normal salt diet. Furthermore, chronic administration of the $\mathrm{AT}_{1}$ receptor antagonist, losartan, markedly attenuated the $\mathrm{I} 3 \mathrm{C}$-induced increase in arterial blood pressure, completely abrogated the decrease in body weight, and prevented that augmentation of ANG II levels in kidney cortex and medulla in rats induced with I3C and maintained on a high salt diet.

Previous studies have demonstrated that kidney ANG II contents of 2K1C Goldblatt hypertensive rats, ANG II-infused hypertensive rats, TGR(mRen2)27 transgenic rats, and hypertensive Cyp1a1-Ren2 transgenic rats are markedly higher than can be explained on the basis of circulating ANG II concentrations even though the kidneys are exposed to markedly elevated arterial blood pressures. ${ }^{28-30}$ In the present study, the rats with malignant hypertension and fed a normal salt diet exhibited substantially elevated ANG II levels in kidney cortex and medulla compared with non-induced controls (Fig. 3). This observation confirms our previous findings that the pathogenesis of ANG II-dependent malignant hypertension in Cyp1a1-Ren2 transgenic rats involves augmentation of total kidney ANG II levels. ${ }^{14}$ Chronic blockade of $\mathrm{AT}_{1}$ receptors with losartan prevented the $\mathrm{I} 3 \mathrm{C}$-mediated augmentation of kidney cortex and medulla ANG II levels indicating that the elevated intrarenal ANG II levels in the rats with malignant hypertension was dependent on activation of $\mathrm{AT}_{1}$ receptors. The augmentation of total kidney ANG II content in the rats with malignant hypertension may have occurred secondary to $\mathrm{AT}_{1}$ receptor-mediated uptake of circulating ANG II and/or $\mathrm{AT}_{1}$ receptor-mediated stimulation of intrarenal angiotensinogen and ANG II generation, such as occurs in ANG II-infused hypertensive rats. ${ }^{20,29}$ Given that $\mathrm{AT}_{1}$ receptors are located on the luminal and basolateral membranes of the proximal tubule as well as in the distal nephron segments and collecting ducts ${ }^{31}$, it is likely that, as with ANG II-infused hypertensive rats, increases in circulating ANG II levels resulting from induction of the Cyp1a1-Ren2 transgene 
are actively taken up by renal tubular cells via $\mathrm{AT}_{1}$ receptors. However, it is also possible that the increased kidney ANG II levels in rats with malignant hypertension occurred, at least in part, as a consequence of stimulation of endogenous renal renin synthesis. In essence, malignant hypertension may have caused renal damage which in turn led to a stimulation of endogenous renin secretion from the juxtaglomerular cells and increased intrarenal ANG II levels. In this regard, we have previously demonstrated that the kidneys of Cyp1a1-Ren2 rats induced with $0.3 \%$ I3C for 7-9 days exhibited myointimal hyperplasia and tubular dilation,

glomerulosclerosis, and tubulointerstitial inflammation and proliferation, particularly in the perivascular areas. ${ }^{27}$ In addition, we recently observed that Cyp1a1-Ren2 transgenic rats with malignant hypertension exhibit maintained JG cell renin immunoreactivity and markedly augmented collecting duct cell renin immunoreactivity. ${ }^{32}$ Collectively, these findings demonstrate that the renal pathological changes that occur 7-9 days after induction of malignant hypertension in Cyp1a1-Ren2 rats primarily consist of inflammation and cellular proliferation in cortical vessels and tubulointerstitium. ${ }^{27}$ Further, the recent finding that renin immunoreactivity in the JG cells was not suppressed and that collecting duct renin immunoreactivity was markedly increased in kidneys of malignant hypertensive rats ${ }^{32}$ indicates that the kidneys of Cyp1a1-Ren2 rats with malignant hypertension are not renindepleted. Such maintained JG renin levels together with the increased collecting duct renin may contribute to augmented intrarenal ANG II levels. One would predict that the morphological changes together with maintained or elevated intrarenal renin levels would likely contribute to the elevated ANG II levels in the renal cortex and medulla in this model, although further studies are required to address this issue. Whatever the mechanism, it is apparent that kidneys of hypertensive Cy1p1a1-Ren2 transgenic rats exhibit an impaired ability to suppress intrarenal ANG II levels appropriately in response to sustained increases in arterial pressure. It is likely that the renal vascular and tubular actions of such inappropriately elevated intrarenal ANG II levels together with the elevated circulating ANG II levels would contribute to an impaired sodium excretory capability and a suppressed pressure natriuretic response to the ANG II-mediated increases in peripheral resistance and arterial pressure. ${ }^{14}$ In this manner, the augmented intrarenal ANG II content would contribute to the pathogenesis of malignant hypertension in Cyp1a1-Ren2 transgenic rats by maintaining an inappropriately high reabsorptive rate and a suppressed pressure natriuresis unresponsive to increased arterial pressure.

Numerous studies have demonstrated that ANG II-dependent hypertensive rats exhibit further increases in arterial pressure when fed a high salt diet. ${ }^{3,4,24}$ Similarly, transient induction of ANG II-dependent hypertension has been shown to result in the development of persistent saltsensitive hypertension in rats. ${ }^{1,2}$ The present data demonstrate that Cyp1a1-Ren2 transgenic rats with inducible ANG II-dependent malignant hypertension similarly exhibit further increases in blood pressure when fed a high salt diet. The rats induced with I3C and fed a high salt diet exhibited a similar decrease in body weight compared with that observed in rats induced with $\mathrm{I} 3 \mathrm{C}$ but fed a normal salt diet. Nevertheless, the present findings demonstrate that Cyp1a1-Ren2 transgenic rats with ANG II-dependent malignant hypertension are saltsensitive. The mechanisms responsible for the salt-sensitivity of the malignant hypertensive rats remains unclear, but are possibly related to the inability to appropriately suppress the activity of the RAS in response to an increase in salt intake. We evaluated this possibility by determining the effects of high salt intake on ANG II levels in kidney cortex and medulla of Cyp1a1-Ren2 rats in which the activity of the RAS was genetically clamped at a high level. In the present study, ANG II levels in kidney cortex and medulla of rats with malignant hypertension fed a high salt diet were not substantively different from those in rats induced with $\mathrm{I} 3 \mathrm{C}$ and fed a normal salt diet (Fig. 3). These findings indicate that high salt diet failed to appropriately suppress kidney ANG II levels. Chronic blockade of $\mathrm{AT}_{1}$ receptors with losartan prevented the I3C-mediated augmentation of kidney cortex and medulla ANG II levels in rats 
with malignant hypertension and fed a high salt diet (Fig. 3) indicating that the elevated intrarenal ANG II levels in these rats was also dependent on activation of $\mathrm{AT}_{1}$ receptors.

The present findings that high salt diet elicited further increases in blood pressure and increases in kidney cortex and medulla ANG II levels in Cyp1a1-Ren2 transgenic rats with ANG IIdependent malignant hypertension are consistent with observations from a variety of previous studies that have demonstrated that ANG II-infused hypertensive rats demonstrate a further increase in blood pressure when fed a high salt $\operatorname{diet}^{3,4,24}$ and that intrarenal ANG II levels, the number of tubulointerstitial ANG II-positive cells, and the severity of the renal inflammatory infiltration are all elevated in the post-ANG II salt-sensitive hypertension rat model. ${ }^{21,22}$ Such an inability to appropriately suppress intrarenal ANG II levels in response to a high salt intake would attenuate the vasodilation and natriuresis normally associated with decreasing intrarenal ANG II levels ${ }^{24}$ and, thereby, prevent the kidney from responding to the high salt intake with an appropriate natriuresis which would result in volume expansion and hypertension. ${ }^{24}$

Similarly, it is possible that in the present study, genetic clamping of the activity of the RAS at a high level would contribute to an inappropriately high level of renal vasoconstriction and sodium reabsorptive capabilities of the tubules and shift the pressure-natriuresis relation to the right which in turn would prevent the kidney from excreting a salt load except at elevated arterial blood pressures and, thereby, contribute to salt-sensitivity. ${ }^{24}$

In the present study, chronic administration of losartan $(100 \mathrm{mg} / \mathrm{l}$ in drinking water $)$ failed to prevent the development of hypertension in rats induced with $0.3 \% \mathrm{I} 3 \mathrm{C}$. This is in contrast to our previous observations that chronic administration of the $\mathrm{AT}_{1}$ receptor antagonist, candesartan $(25 \mathrm{mg} / \mathrm{L}$ in drinking water), completely prevented the development of malignant hypertension in Cyp1a1-Ren2 transgenic rats. ${ }^{14}$ The reason for this disparity remains unclear but could be due to the fact that an insufficiently high dose of losartan was used in the present study to elicit complete or near complete blockade of $\mathrm{AT}_{1}$ receptors. However, it is worth emphasizing that the dose of losartan used in the present study completely attenuated the I3Cinduced decrease in body weight, prevented the increase in blood pressure induced by high salt diet, and abrogated the effects of high salt diet to increase the ANG II levels in kidney cortex and medulla in Cyp1a1-Ren2 rats. This indicates that the dose of losartan used in the present study elicited substantive blockade of $\mathrm{AT}_{1}$ receptors. An alternative possibility is that, in contrast to candesartan which is a non-competitive $\mathrm{AT}_{1}$ receptor antagonist, losartan is a competitive antagonist of the $\mathrm{AT}_{1}$ receptor and that the markedly elevated plasma ANG II levels were able to prevent losartan from eliciting full blockade of endogenous $\mathrm{AT}_{1}$ receptors which allowed blood pressure to increase in Cyp1a1-Ren2 rats induced with I3C alone. Additional studies are required to address this issue.

In summary, the present findings demonstrate that a high dietary salt intake markedly exacerbates the increase in arterial blood pressure in Cyp1a1-Ren2 transgenic rats with inducible ANG II-dependent malignant hypertension. The data also show that chronic blockade of $\mathrm{AT}_{1}$ receptors with losartan substantially attenuates the effects of high salt diet to exacerbate the increase in arterial pressure and prevents the augmentation of kidney cortex and medulla ANG II levels in Cyp1a1-Ren2 rats induced with I3C and fed a high salt diet. Thus, inappropriate activation of $\mathrm{AT}_{1}$ receptors by ANG II contributes to the augmented blood pressure and elevated kidney tissue ANG II levels that occur in Cyp1a1-Ren2 transgenic rats with malignant hypertension and maintained on a high salt diet.

\section{Acknowledgments}

The authors would like to thank Porcha D. Davis, Dale M. Seth, and Weijian Shao for excellent technical assistance. We also thank Dr. Barb Mickelson, Harlan-Teklad, for help with the design and production of the I3C-containing rat diet. This study was supported by a grant from Merck and Co. (Proposal \# 33517), The Tulane COBRE in Hypertension and Renal Biology (NCRR 2P20RR017659-06), and NHLBI grant HL26371. 
This study was supported by a grant from Merck and Co. (Proposal \# 33517), The Tulane COBRE in Hypertension and Renal Biology (NIH: 2P20RR017659-06), and NHLBI grant HL26371.

\section{References}

1. Lombardi D, Gordon KL, Polinsky P, et al. Salt-sensitive hypertension develops after short-term exposure to angiotensin II. Hypertension 1999;33:1013-1019. [PubMed: 10205240]

2. Howard LL, Patterson ME, Mullins JJ, et al. Salt-sensitive hypertension develops after transient induction of ANG II-dependent hypertension in Cyp1a1-Ren2 transgenic rats. Am J Physiol Renal Physiol 2005;288:F810-F815. [PubMed: 15585671]

3. Zhao X, Pollock DM, Inscho EW, et al. Decreased renal cytochrome P450 2C enzymes and impaired vasodilation are associated with angiotensin salt-sensitive hypertension. Hypertension 2003;41(2): 709-714. [PubMed: 12623984]

4. Zhao X, Pollock DM, Zeldin DC, et al. Salt-sensitive hypertension after exposure to angiotensin is associated with inability to upregulate renal epoxygensases. Hypertension 2003;42(2):775-780. [PubMed: 12900436]

5. Kantachuvesiri S, Fleming S, Peters J, et al. Controlled hypertension, a transgenic toggle switch reveals differential mechanisms underlying vascular disease. J Biol Chem 2001;276:36727-36733. [PubMed: 11448960]

6. Campbell SJ, Carlotti F, Hall PA, et al. Regulation of the CYP1A1 promoter in transgenic mice: an exquisitely sensitive on-off system for cell specific gene regulation. J Cell Sci 1996;109:2619-2625. [PubMed: 8937980]

7. Forrester LM, Henderson CJ, Glancey MJ, et al. Relative expression of cytochrome P450 isoenzymes in human liver and association with the metabolism of drugs and xenobiotics. Biochem $\mathrm{J}$ 1992;281:359-368. [PubMed: 1736885]

8. Smith JD, Wong E, Ginsberg M. Cytochrome P450 1A1 promoter as a genetic switch for the regulatable and physiological expression of a plasma protein in transgenic mice. Proc Natl Acad Sci USA 1995;92:1926-11930. [PubMed: 7892201]

9. Gelboin HV. Benzo[alpha]pyrene metabolism, activation and carcinogenesis: role and regulation of mixed-function oxidases and related enzymes. Physiol Rev 1980;60:1107-1166. [PubMed: 7001511]

10. Jellinck PH, Forkert PG, Riddick DS, et al. Ah receptor binding properties of indole carbinols and induction of hepatic estradiol hydroxylation. Biochem Pharmacol 1993;45:1129-1136. [PubMed: 8384853]

11. Loub WD, Wattenberg LW, Davis DW. Aryl hydrocarbon hydroxylase induction in rat tissues by naturally occurring indoles of cruciferous plants. J Natl Cancer Inst 1975;54:985-988. [PubMed: 1127728]

12. Pelkonen O, Nebert DW. Metabolism of polycyclic aromatic hydrocarbons: etiologic role in carcinogenesis. Pharmacol Rev 1982;34:189-222. [PubMed: 6287505]

13. Fujii-Kuriyama Y, Masatsuga E, Junsei M, et al. Polymorphic forms of the Ah receptor and induction of the CYP1A1 gene. Pharmacogenetics 1995;5:149-153.

14. Mitchell KD, Bagatell SJ, Miller CS, et al. Genetic clamping of renin gene expression induces hypertension and elevation of intrarenal Ang II levels of graded severity in Cyp1a1-Ren2 transgenic rats. Journal of the Renin Angiotensin Aldosterone System 2006;7(2):74-86. [PubMed: 17083061]

15. Fox J, Guan S, Hymel AA, et al. Dietary Na and ACE inhibition effects on renal tissue angiotensin I and II and ACE activity in rats. Am J Physiol Renal Physiol 1992;262:F902-F909.

16. Hodge G, Ye VZC, Duggan KA. Dysregulation of angiotensin II synthesis is associated with salt sensitivity in the spontaneously hypertensive rat. Acta Physiol Scand 2002;174:209-215. [PubMed: 11906319]

17. Kobori H, Nishiyama A, Abe Y, et al. Enhancement of intrarenal angiotensinogen in Dahl saltsensitive rats on high salt diet. Hypertension 2003;41:592-597. [PubMed: 12623964]

18. Kobori H, Harrison-Bernard LM, Navar LG. Enhancement of angiotensinogen expression in angiotensin II-dependent hypertension. Hypertension 2001;37:1329-1335. [PubMed: 11358949]

19. Kobori H, Nishiyama A, Harrison-Bernard LM, et al. urinary angiotensinogen as an indicator of intrarenal angiotensin status in hypertension. Hypertension 2003;41:42-49. [PubMed: 12511528] 
20. Kobori H, Prieto-Carrasquero MC, Ozawa $\mathrm{Y}$, et al. $\mathrm{AT}_{1}$ receptor mediated augmentation of intrarenal angiotensinogen in angiotensin II-dependent hypertension. Hypertension 2004;43:1126-1132. [PubMed: 15037565]

21. Franco M, Martinez F, Rodriguez-Iturbe, et al. Angiotensin II, interstitial inflammation, and the pathogenesis of salt-sensitive hypertension. Am J Physiol Renal Physiol 2006;291:F1281-1287. [PubMed: 16868307]

22. Franco M, Martinez F, Quiroz Y, et al. Renal angiotensin II concentration and interstitial infiltration of immune cells are correlated with blood pressure levels in salt-sensitive hypertension. Am J Physiol Renal Physiol 2007;293:R251-R256.

23. Gonzalez-Villalobos RA, Seth DM, Satou R, et al. Intrarenal angiotensin II and angiotensinogen augmentation in chronic angiotensin II-infused mice. Am J Physiol Renal Physiol 2008;295:F772F779. [PubMed: 18579707]

24. Osborn JW, Ariza-Nieto P, Collister JP, et al. Responsiveness vs. basal activity of plasma ANG II as a determinant of arterial pressure salt-sensitivity. Am J Physiol Heart Circ Physiol 2003;285:H2142H2149. [PubMed: 12881218]

25. Braam B, Mitchell KD, Fox J, et al. Proximal tubular secretion of angiotensin II in rats. Am J Physiol Renal Physiol 1993;264:F891-F898.

26. Whitworth CE, Fleming S, Kotelevtsev Y, et al. A genetic model of malignant phase hypertension in rats. Kidney Int 1995;47:529-535. [PubMed: 7723238]

27. Graciano ML, Mouton CR, Patterson ME, et al. Renal vascular and tubulointerstitial inflammation and proliferation in Cyp1a1-Ren2 transgenic rats with inducible ANG II-dependent malignant hypertension. Am J Physiol Renal Physiol 2007;292:F1858-F1866. [PubMed: 17344186]

28. Guan S, Fox J, Mitchell KD, et al. Angiotensin and angiotensin converting enzyme tissue levels in two-kidney, one clip hypertensive rats. Hypertension 1992;20:763-767. [PubMed: 1333445]

29. Zou L, Imig JD, Von Thun AM, et al. Receptor-mediated intrarenal ANG II augmentation in ANG II-infused hypertensive rats. Hypertension 1996;28:669-677. [PubMed: 8843896]

30. Mitchell KD, Jacinto SM, Mullins JJ. Proximal tubular fluid, kidney, and plasma levels of angiotensin II in hypertensive ren-2 transgenic rats. Am J Physiol Renal Physiol 1997;273:F246-253.

31. Harrison-Bernard LM, Navar LG, Ho MM, et al. Immunohistochemical localization of ANG II $\mathrm{AT}_{1}$ receptor in adult rat kidney using a monoclonal antibody. Am J Physiol Renal Physiol 1997;273:F170-F177.

32. Prieto MC, Botros FT, Martin VL, et al. Increased collecting duct renin protein expression in Cyp1a1Ren2 transgenic rats with inducible ANG II-dependent malignant hypertension. FASEB J 2009;23:1016.3. 


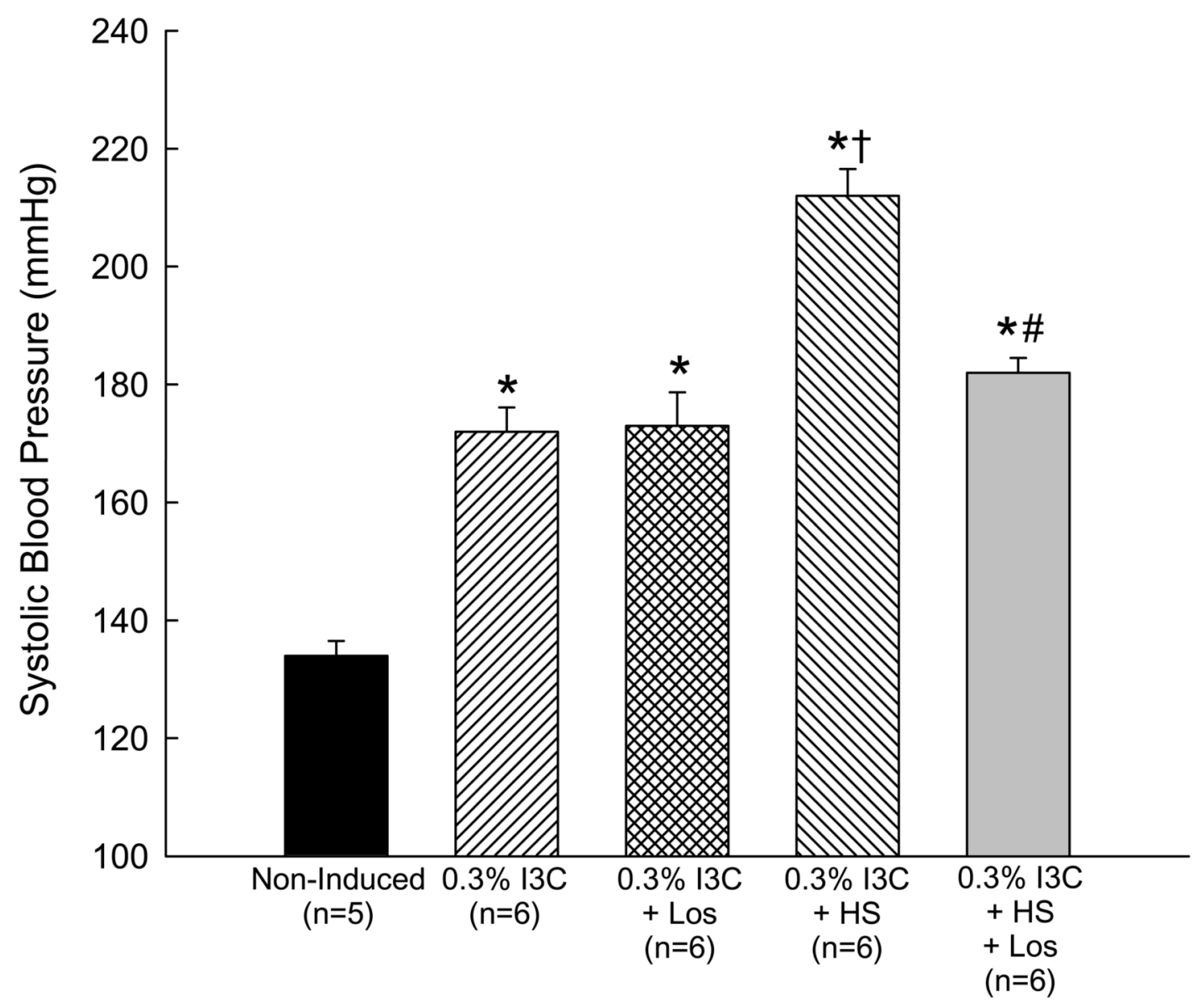

FIG. 1.

Conscious systolic blood pressures of non-induced Cyp1a1-Ren2 rats (Non-induced); Cyp1a1Ren 2 rats fed a normal-salt diet containing $0.3 \%$ I3C for 10 days $(0.3 \%$ I3C); Cyp1a1-Ren2 rats induced for 10 days with $0.3 \% \mathrm{I} 3 \mathrm{C}$ and treated with the $\mathrm{AT}_{1}$ receptor antagonist, losartan (Los; $100 \mathrm{mg} / \mathrm{L}$ in drinking water) $(0.3 \% \mathrm{I}$ C+Los); Cyp1a1-Ren 2 rats induced with $\mathrm{I} 3 \mathrm{C}$ and fed a high salt diet (HS) $(0.3 \%$ I3C+HS); and Cyp1a1-Ren2 rats induced with $0.3 \%$ I3C, fed a HS diet and treated with losartan (Los; $100 \mathrm{mg} / \mathrm{L}$ in drinking water) $(0.3 \% \mathrm{I} 3 \mathrm{C}+\mathrm{HS}+\mathrm{Los})$. $* \mathrm{P}<0.001$ vs. non-induced; $\dagger \mathrm{P}<0.001$ vs. $0.3 \% \mathrm{I} 3 \mathrm{C}$; $\# \mathrm{P}<0.001$ vs. $0.3 \% \mathrm{I} 3 \mathrm{C}+\mathrm{HS}$. 


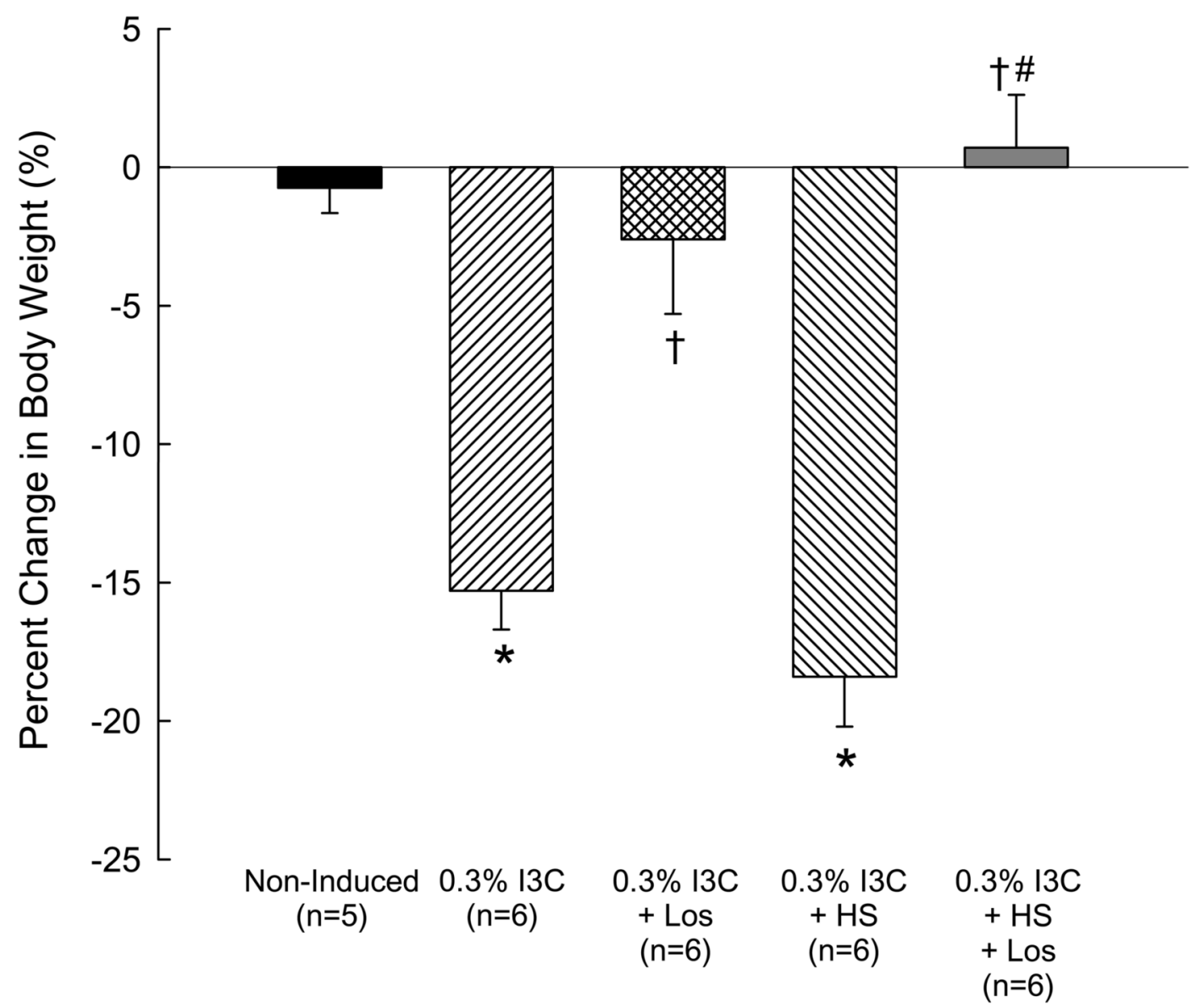

Fig. 2.

Percent change from baseline in body weights of non-induced Cyp1a1-Ren2 rats (Noninduced); Cyp1a1-Ren2 rats fed a normal-salt diet containing $0.3 \% \mathrm{I} 3 \mathrm{C}$ for 10 days $(0.3 \% \mathrm{I} 3 \mathrm{C})$; Cyp1a1-Ren2 rats induced for 10 days with $0.3 \% \mathrm{I} 3 \mathrm{C}$ and treated with the $\mathrm{AT}_{1}$ receptor antagonist, losartan (Los; $100 \mathrm{mg} / \mathrm{L}$ in drinking water) (0.3\% I3C+Los); Cyp1a1-Ren2 rats induced with I3C and fed a high salt diet (HS) (0.3\% I3C+HS); and Cyp1a1-Ren2 rats induced with $0.3 \% \mathrm{I} 3 \mathrm{C}$, fed a HS diet and treated with losartan (Los; $100 \mathrm{mg} / \mathrm{L}$ in drinking water) $(0.3 \%$ $\mathrm{I} 3 \mathrm{C}+\mathrm{HS}+\mathrm{L}$ os). ${ }^{*} \mathrm{P}<0.001$ vs. non-induced; $\uparrow \mathrm{P}<0.001$ vs. $0.3 \% \mathrm{I} 3 \mathrm{C} ; \# \mathrm{P}<0.001$ vs. $0.3 \% \mathrm{I} 3 \mathrm{C}$ $+\mathrm{HS}$. 

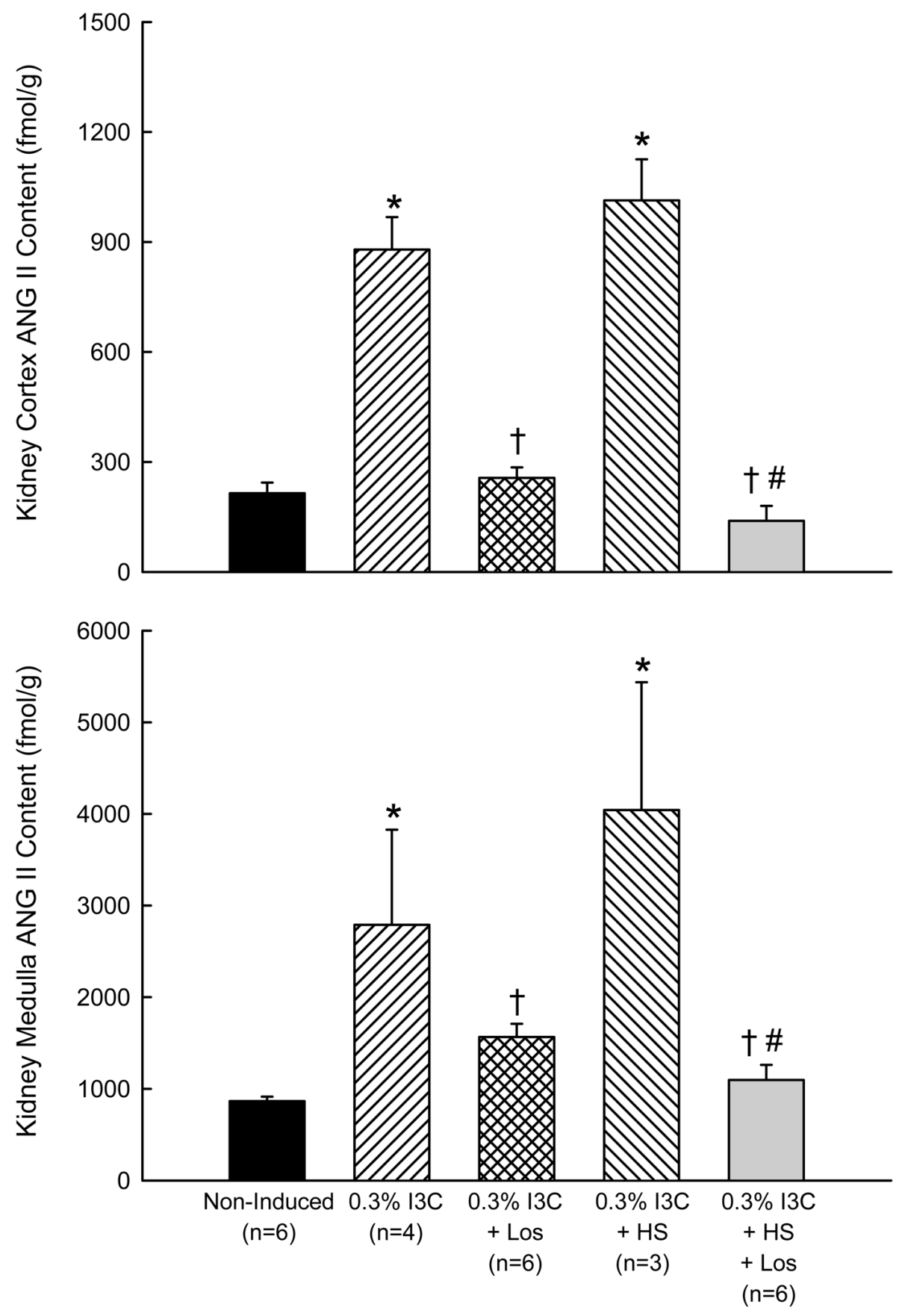

FIG. 3.

Effects of I3C, I3C+Los, I3C+HS, and I3C+HS+Los on kidney cortex and medulla ANG II contents in Cyp1a1-Ren2 transgenic rats. $* \mathrm{P}<0.001$ vs. non-induced; $\uparrow \mathrm{P}<0.001$ vs. $0.3 \% \mathrm{I}$ C; \# $\mathrm{P}<0.001$ vs. $0.3 \%$ I3C+HS. 